\title{
LETTERS
}

\section{Data interoperability is far more valuable and feasible than a single electronic health record}

I agree fully with Dr. Persaud ${ }^{1}$ that health data should be stored and administered at a national level or, failing that, at a provincial level. This would eliminate costly retesting, reduce medical errors, improve the efficiency of health care provision, and allow for improved research and quality monitoring in the health care system. It is truly unfortunate that the greatest promise of electronic health records has not yet been realized because of the diverse set of incompatible systems implemented by siloed information technology departments and care providers with no national or provincial direction.

The solution proposed by Dr. Persaud, however, is fundamentally flawed and lacks insight into the realities and complexities that have precluded such an approach in the past. For example, requiring a single national system for electronic health records would hold all Canadians, health care providers and institutions hostage to a single corporate entity. How would all the varying requirements of every stakeholder be collected and negotiated into a manageable service contract? Who would pay for voiding all existing service contracts for electronic health records with providers who were not selected for the single national service?

We need to work toward alternative but feasible solutions to achieve the stated goals.

In my opinion, the best solution is centrally managed data with interoperability standards and requirements for querying and storing health data. Electronic health record systems implemented across the country would be required and certified to query and store a comprehensive set of health data attributes using the national database. This approach permits local customization of these systems, and safe migration from siloed local databases to the national database without forcing all stakeholders out of their existing service contracts.
Database technology has advanced tremendously in the last decade, with flexible horizontally scaling NoSQL (not only structured query language) systems becoming commonplace in the technology world. These systems permit centralization of data without compromising query performance on enormous data sets or flexibility of database architecture.

Substantial capital investment and technical leadership will still be required to achieve this. I fear that in the current environment of increasing austerity, gaining traction on this initiative will remain a challenge even if cost-effective in the mid to long term.

\section{David M. Burns B.Eng MD}

Orthopedic surgery resident, University of Toronto, Toronto, Ont.

Cite as: CMAJ 2019 May 27;191:E587. doi: 10.1503/cmaj.71915

\section{Reference}

1. Persaud N. A national electronic health record for primary care. CMAJ 2019;191:E28-9.

Competing interests: None declared. 